\title{
Cluster Policy Based on Key National Clusters - a Case of Poland
}

\author{
Anna H. JANKOWIAK \\ Wroclaw University of Economics, Wroclaw, Poland \\ anna.jankowiak@ue.wroc.pl
}

\begin{abstract}
The paper discusses cluster policy or cluster-based policy as a widely used phenomenon in many countries of the world, and as an element of innovation, industrial policy or broadly understood development policy. It can be noticed by observations of advanced cluster policies existing in highly developed countries that in the early phase of existence of such programs, all clusters and cluster initiatives receive support. At a later stage, however, key clusters are selected, which receive significant financial, training, and infrastructural support, and which are selected in national competitions. The paper aims to present a cluster policy based on the functioning of key clusters on the example of Poland. The article will review the latest literature on cluster policy, tools relevant in various countries will be presented, and then the selection and support for key clusters will be presented on the example of Poland. In the last part, an attempt will be made to assess the effectiveness and validity of the presented model of cluster policy which is based on key clusters in Poland.
\end{abstract}

Keywords: Cluster Policy, Key National Clusters, Poland.

\section{Introduction}

Cluster policy or cluster-based policy is widely used in many countries of the world as an element of innovation, industrial policy or broadly understood development policy. Cluster policy is a collection of various tools used to support cluster activities in individual national economies. It can be noticed by observations of advanced cluster policies existing in highly developed countries that in the early phase of existence of such programs, all clusters and cluster initiatives receive support. At a later stage, however, key clusters are selected, which receive significant financial, training, and infrastructural support, and which are selected in national competitions. The paper aims to present a cluster policy based on the functioning of key clusters on the example of Poland. Currently, cluster policy analyses focus on the policy as a whole of activities, without specifying the functioning of key clusters constituting at the same time a specific tool and the target group of beneficiaries of this policy. The article aims to fill this gap, because, according to the author's opinion, the creation and existence of key clusters is a factor shaping the cluster policy and its effectiveness and efficiency in the redistribution of resources including financial resources. The article will review the 
latest literature on cluster policy, tools relevant in various countries will be presented, and then the selection and support for key clusters will be presented on the example of Poland. In the last part, an attempt will be made to assess the effectiveness and validity of the presented model of cluster policy which is based on key clusters in Poland.

\section{Cluster Policy - Theoretical Approach}

It can encounter definition problems of cluster policy identical with the difficulty in clearly defining the concept of the cluster. Just as two identical clusters in different locations cannot be created, which results from the diverse external environment of the cluster, a universal set of cluster policy tools cannot be created as well. This is mainly due to the fact that national economies differ widely and there are different goals and assumptions of this policy. Individual national or regional governments have a different level of, for example, financial outlays, which can be an element of support for national clusters. The existence of many different models is also related to the different affiliation of cluster policy to innovation, development, industrial policy, etc. For this reason, it can be assumed that "cluster policy is multi-dimensional, multi-instrument policy, informed by a mix of rationales. The development of clusters, therefore, means different things in different places" [12].

An important element in defining a cluster policy is identifying the level that this policy applies to. According to Lehmann and Menter, "Public cluster-based policy and cluster development could be defined as the policy-making use of the regional or local level in order to pursue regional or national goals" [9]. According to the European Union definition "modern cluster policies aim to put in place a favourable business ecosystem for innovation and entrepreneurship in which new winners can emerge and thus support the development of new industrial value chains and "emerging industries" [15].

By many different definitions of cluster policy, one can assume a certain generalisation that links cluster policy with stimulating broadly understood competitiveness of cluster entities and regions in which clusters operate. It is also connected with deepening the specialisation of regions (smart specialisation), with innovation and regional development. „Cluster policy can be placed somewhere between a nationally oriented industry policy that promotes a narrowly defined set of industries, or "national champions", and a broad regional innovation policy prioritising the development of regional capabilities and regional institutional thickness " [12].

According to Borrás there are following cluster policy categories, but it can be concluded that the differences are sometimes hard to identified [1]:

- creationist - in this approach cluster policy can be understood as a set of tools for the creation of new clusters. the policy aims to address the problems connected with the specific dynamics of the clusters and the policy embedded in the wider state society - economy interactions,

- narrow - this approach is based on the more practical way of thinking about cluster policy, where all the instruments are connected with the public support actions, 
- top - down - the cluster policy should be focused on formal programs and designed public actions created on national - regional level,

- evolutionary - the task for cluster policy is to upgrade the knowledge base, the competences, and the learning abilities of the territory to improve the level of competitiveness of a cluster,

- network - in this approach the links between public and private activities are needed and essential to the development of clusters.

Cluster policy, regardless of its category, has been widely used for many years, and now one can notice its dynamic development and its more and more conscious application. Cluster policies, started to be implemented in the early 1990s, there are three main stages in their development that can be observed:

- The early 1990s: pioneer countries and regions attentively studied the cluster approach and took risks to develop competitiveness or innovation orientated policies based on it.

- The mid-1990s to mid-2000s: this period of 'cluster policy entrepreneurs' was characterised by first results from pioneer countries and a general broadening of knowledge on the possibilities for developing a successful regional policy through clusters.

- The mid-2000s till around 2010: cluster policy is increasingly mainstream as more and more regions, and countries introduce the policy due to successful results of previous implementations. The question changes from whether or not to implement, towards how to implement to achieve the most effective results [8].

- Around 2010 onward: the integration of cluster efforts into regional policies. The smart specialisation approach outlines the need to foster structural change alongside a focus on regions' existing strength [10]. The cluster policy is strongly connected with innovation policy and is carried out more consciously.

Just as the definition of cluster policy is varied, so also does not exist one defined set of tools for this policy. This is due to the specificity of each country, the level at which the cluster policy is implemented, the financial resources available for clusters, and even the understanding of the concept of the cluster in individual countries. However, the following tools that are successfully used in well-developed cluster policies can be indicated [13]:

- providing incentives for exports,

- attracting investment resources,

- regulation of the labour market, encouraging the growth of human capacity,

- targeted regulation of innovation activity,

- stimulation of research activities to the needs of industry,

- budget allocations knowledge-intensive businesses,

- tax reduction on investments in innovation,

- development of the scientific and technological partnership,

- providing tax credits and preferential taxation of companies carrying out a program of innovation, 
- involvement of the initial capital,

- encourage the development of highly specialised regions,

- the attraction of foreign advanced technologies,

- investing in human development,

- formation of the level of development of interaction between scientific institutions and industries.

According to Nishimura and Okamuro cluster policy tools can be divided into six groups, and those are as follow: network formation, R\&D support, incubation function, marketing support, financial support, fostering human resources [11].

\section{Cluster Policy in Poland}

Cluster-based efforts or cluster policy, in general, have already become a natural part of economic policies. This policy is visible not only at the regional level but nowadays also at the national level as a component of innovation and SME support policies in the EU countries [13]. Support for the development of clusters in the European Union has been included in the Europe 2020 Strategy, which assists member states in strengthening smart specialisation and cluster initiatives for the rejuvenation of Europe's industry. In the Europe 2020 Strategy, under the flagship initiative: „An industrial policy for the globalisation era”, The Commission undertook ,to improve the business environment, especially for SMEs, including through reducing the transaction costs of doing business in Europe, the promotion of clusters and improving affordable access to finance" [11]. Whereas under the flagship initiative: „Innovation Union” the task of strengthening cooperation between universities, the research community and business has been put forward in the Member States, which is a practical fulfilment of the conditions for the definition of clusters' activities.

Cluster policy in Poland results in a way from European policy and is carried out in similar time horizons, which is most often the result of the functioning of EU budgets. Assumptions for current activities have been included in such documents as National Development Strategy until 2020, Enterprise Development Program for 2020 and Directions and assumptions of cluster policy in Poland by 2020. In the National Development Strategy until 2020, clusters are perceived as a factor improving the country's competitiveness and deepening regional specialisation. In this document and many others, clusters are to constitute an important lever for the development of Polish exports, both in traditional and modern industries, such as ICT or automotive. The task of active cluster policy will be, inter alia, to support the most innovative and showing the highest potential for development of Polish clusters that are able to create highlycompetitive products and services constituting Polish and European export specialities [16].

Principal aim of the Polish cluster policy is to strengthen the innovativeness and competitiveness of Polish economy through intensified cooperation, interactions and knowledge transfer (that is through providing support for existing and newly created clusters) as well as through supporting the development of key 
economic specializations (that means selecting key national and regional clusters and focusing part of public support on them).

The achievement of the principal aim involves the fulfilment of the following specific aims [2]:

- stimulation of internal interactions, knowledge transfer and cooperation as well as the creation of necessary social capital;

- expansion of the external networking of clusters and entities operating within them, especially in cross-sector and international dimension,

- strengthening of joint and integrated strategic planning processes within clusters,

- the increase of the number of innovative goods and services offered on domestic and international markets by companies and entities operating within clusters, which should lead, among other things, to the growth of export,

- the mobilisation of private investment in clusters, including the creation of new companies and inflow of foreign investment as well as increasing private spending on R\&D and innovation-oriented activities,

- the development of the ecosystem of supporting institutions (e.g. education and research institutes, technological parks and technology transfer centers, etc.) and better customisation of their offer and activities to the needs of companies operating within the clusters,

- boosted the effectiveness of using public funds by their concentration and obtaining synergy between different policies and support instruments (e.g. concerning infrastructure development, human capital, R\&D, promotion, internationalisation, etc.).

The functioning of clusters will be based on a market and participatory model, meaning the leading role of the private sector in their initiation, financing and management. It is assumed that there are three types of clusters: local clusters (shaping the local economic ecosystem), key regional clusters (of significant importance for the economy of the regions) and key national clusters (recognisable and competitive on a global scale). Depending on the scale of operation, cluster policy will offer diverse support (see figure 1). Currently, a significant part of cluster support as part of cluster policy is addressed to key clusters, which will be discussed in the next section of the article. 


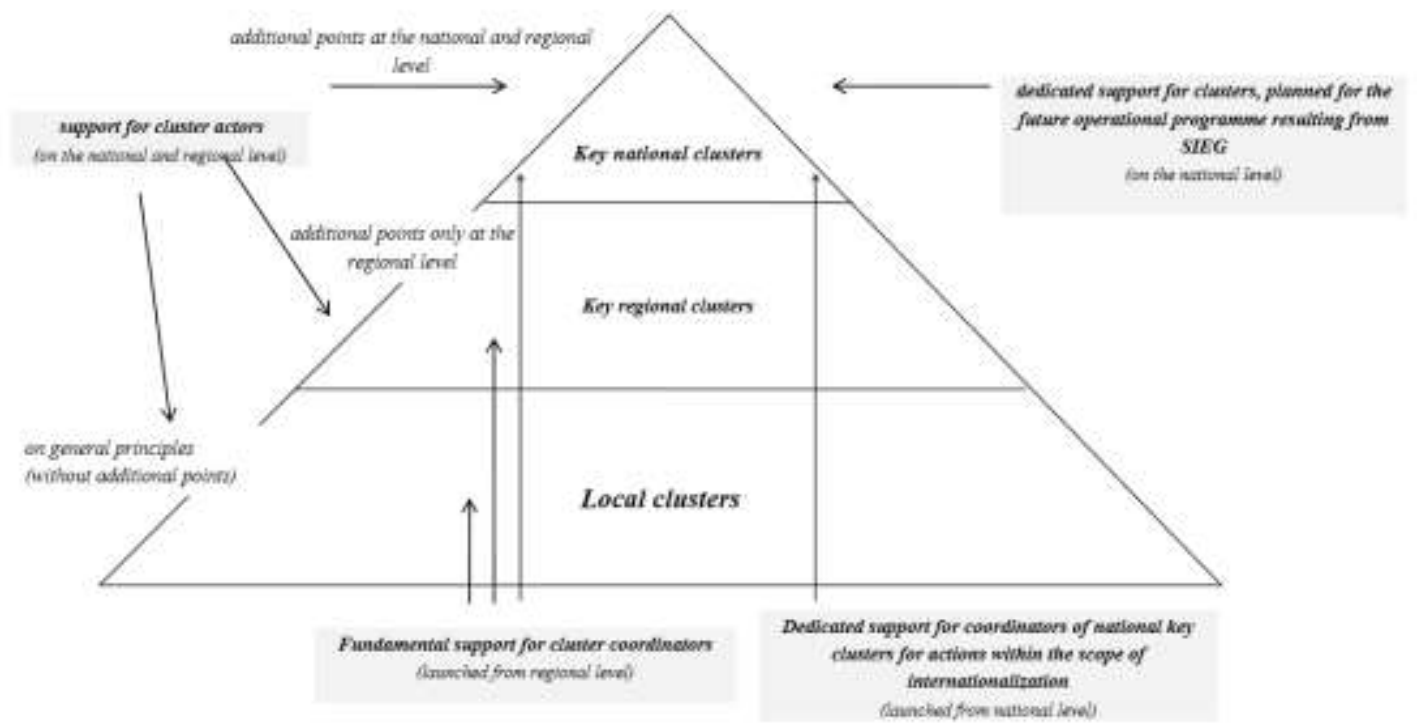

Fig. 1. Map of cluster support in Poland [2].

\section{$4 \quad$ Key National Clusters - a Case of Poland}

The cluster policy model based on the support of key clusters is implemented in several national economies. An example is Canada, where only five superclusters have received support lately. In the central part of Europe, two countries, Hungary and Poland, introduced programmes of selection and additional support for clusters relevant to the whole economy. In Hungary, the government created the Accredited Innovation Clusters and to be in this group cluster has to operate for at least 3 years, has 20 members as a minimum, 15 of which must operate in the cluster for more than two years, and the small and medium-sized enterprises must represent at least $75 \%$ of all the cluster entities. The Czech Republic has not introduced the programme of key clusters' selection, as it decided not to create groups of privileged clusters, believing that the authorities should offer the same opportunities to all the actors. In Slovakia, for the time being, the theoretical fundamentals are being developed, and the clusters crucial to the economy need to meet very specific criteria [6].

In Poland, there are currently 16 key national clusters that have been selected in the national competition (see figure 2). The Organizer of the Competition for the status of the Key National Cluster (KNC) is the Ministry of Development, which runs the Competition in cooperation with the Polish Agency for Enterprise Development (PARP). In the first round of the Competition for KNC status, 22 applications were submitted, on 24 September 2015, the minister competent for economy approved the list of seven Key National Clusters. The call for proposals in the second round of the Competition ended in July 2016, and the Minister of Development approved the list of the next $9 \mathrm{KNC}$. The third round of the competition is currently open, which will end 
at the end of September 2018 and is addressed to those key clusters that lose their key status in 2018.

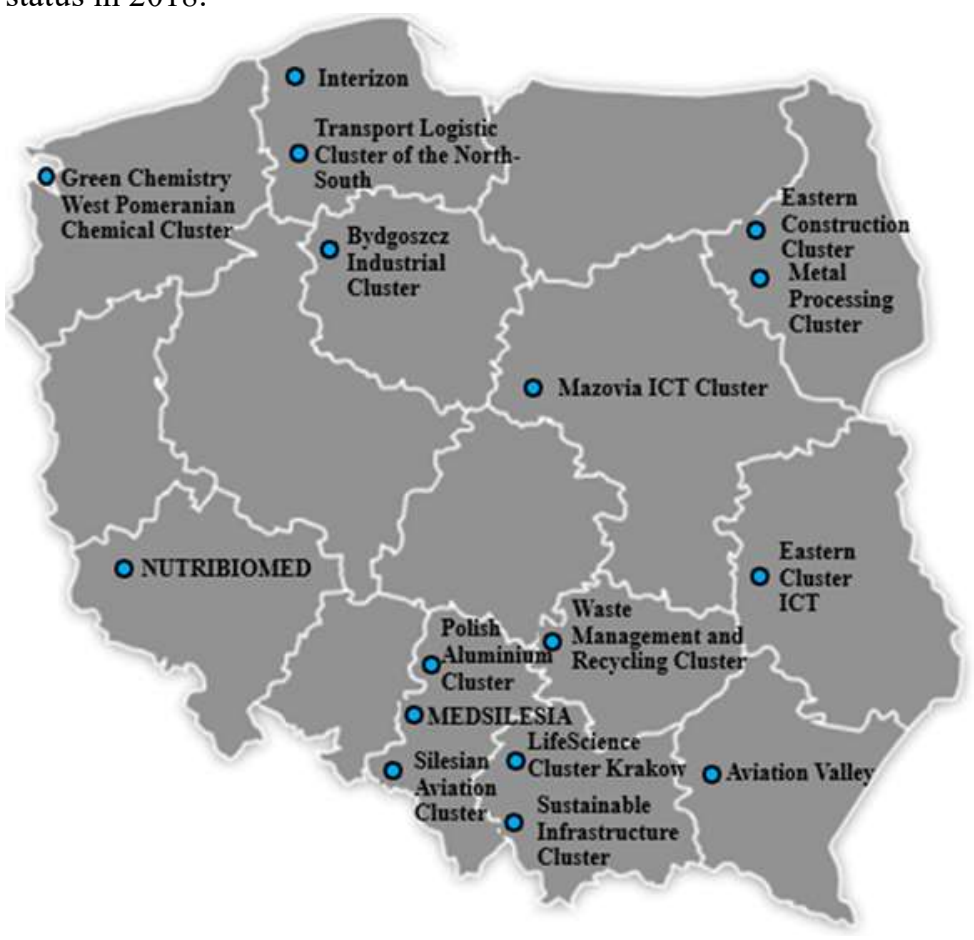

Fig. 2. Key National Clusters in Poland (end of September 2018).

Key National Cluster in Poland is a cluster of significant importance for the national economy and high international competitiveness. Key National Cluster is identified at the national level, including based on criteria regarding critical mass, development and innovation potential, past and planned cooperation as well as statement and potential of the coordinator. According to the guidelines of Key National Cluster in Poland, they are characterised by the following features [4]:

- cluster size - at least 51 entities should be gathered in a key cluster, of which $70 \%$ should be enterprises. By far the most should be small and medium enterprises, large ones can only be 5 , and research units at least 3 ,

- employment in a cluster - at least 3,000 people should be employed in the cluster,

- members' activity - the cluster should have a formal structure and strategy, the cluster members should provide each other services, and the cluster should have one project co-financed from the EU funds jointly implemented at the time of applying,

- territorial concentration - cluster entities should not be located further away from the coordinator's seat than $150 \mathrm{~km}$,

- cluster specialisation - the cluster is part of the smart specialisation of the country and has a great impact on regional development, 
- R \& D - the cluster should have completed at least four research projects in the last two years,

- innovativeness - in the cluster, there should be at least three companies like start-up and spin-off, and there should be at least three innovations covered by legal protection introduced,

- financial resources - the cluster should be financed in 30\% from private sources,

- internationalization - the cluster should have at least medium activity and recognition on international markets, and the share of exports in the sales structure should be at least $30 \%$,

- cluster management - the cluster should prove at least three years of operation history at the time of application.

The process of identifying and supporting key clusters takes place in three stages (see figure 3 ). In the first stage, clusters are obliged to carry out detailed analyses, prepare long-term strategies and action plans, describe the activities undertaken and planned, and methods of cluster structure management. In the second stage, the national key clusters are selected, which, after a positive recommendation, receive this status for 3 or 5 years. The last stage in this process, and at the same time the first stage of proper activities supporting clusters, is the allocation of support depending on the cluster's goals and the scope of their operation.

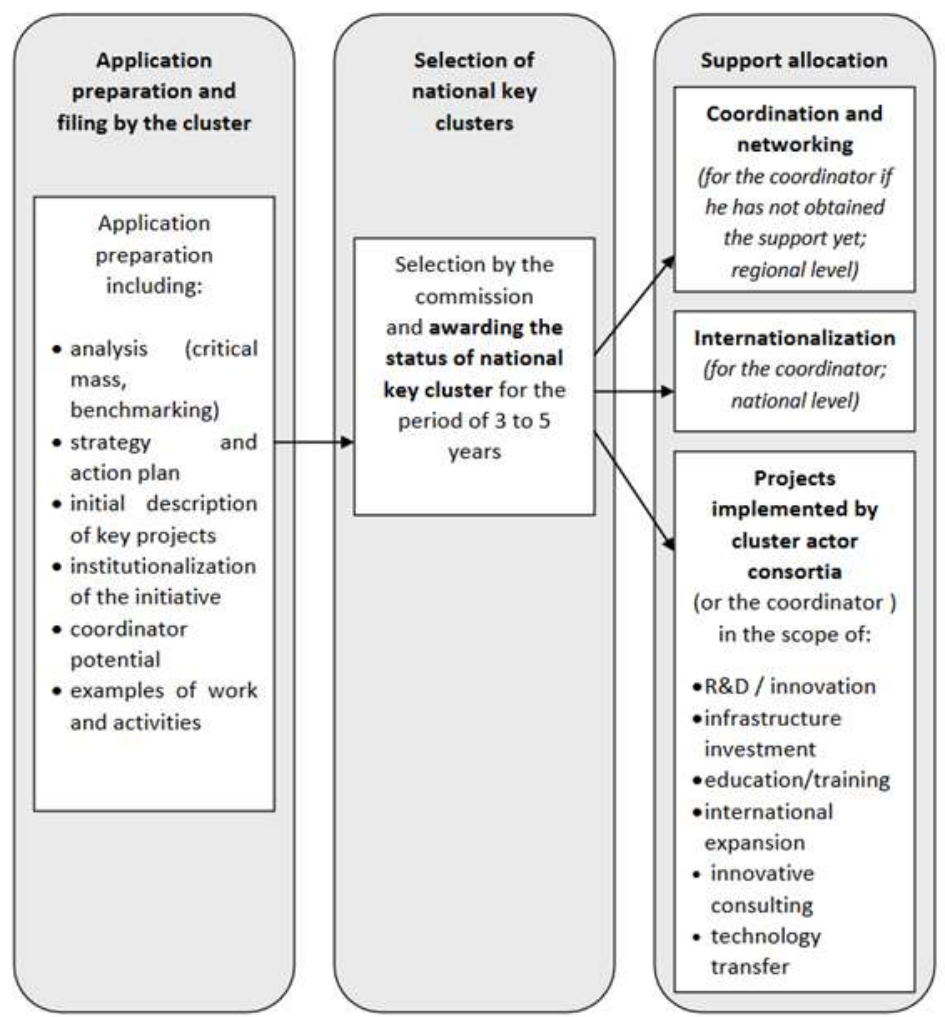

Fig. 3. The process of selecting and supporting national key clusters in Poland [13]. 


\section{$5 \quad$ Assessment of Cluster Policy Based on Key Clusters in Poland}

According to the assumptions of the Polish Agency for Enterprise Development, a cluster policy model based on key clusters should bring the following benefits [5]:

- intensified development of clusters - strong, competitive clusters in the international arena,

- intensified development of regions - dominant clusters support the development of regions, industries operating in them, create a culture and develop the entrepreneurial spirit in the region, contribute to the growth of the number of new companies and employment growth and a decline in unemployment,

- smart specialisation - through the selection of the $\mathrm{KNC}$, the specialisation strategy is deepened, the aim of which is to strengthen strong industries that have the best prospects for development in the future. It can, therefore, be assumed that it is a transfer of economic strategies and good business practices to the ground of economic policy, including cluster policy,

- the effectiveness of subsidies - through the distribution of funds among the KNC, it is possible to achieve effective spending of limited funds on the most resilient and promising further development of the enterprise.

The effects assumed in the framework of the Polish cluster policy seem to have economic justification and result from the development strategies recommended by the European Union. On the one hand, these are actions aiming at increasing the scale of development of selected clusters and regions in which they operate, on the other hand, they are too useful in deepening micro and macroeconomic smart specialisation. However, there are a few weaknesses to these assumptions. These are hard to measure benefits, the effectiveness of which will be complicated to evaluate. One of the assumptions is to improve the efficiency of spending funds, which will be directed only to a narrow group of entities. It will certainly be easier to control the flow of funds, as they will reach no more than a dozen recipients at the same time, but the costs of evaluating key clusters also seem to be definitely higher (for example, international recognition will have to be measured on a large group of recipients located in different countries).

As mentioned earlier, there are 16 key clusters in Poland, and most of them are also clusters belonging to the European category of gold, silver or brown clusters. The choice of these clusters within the KNC from among about 130 clusters currently operating in Poland has strengthened already strong Polish clusters, which on the one hand may contribute to the creation of powerful entities competing successfully internationally, but on the other hand, may hamper the development of other clusters in the national economy. A strong focus on only the largest initiatives can lead to a situation in which newly formed clusters, created for example in very modern industries, will not be able to obtain funding for their activities. Therefore their development will be limited due to the use of cluster policy tools. Key clusters receive their status for up to 5 years, which in the dynamically changing global economy and 
the international environment may give rise to concerns about the right choice of the industry for financial support. There is, therefore, a justified fear that by selecting key clusters, invests in strong clusters, but not necessarily forward-looking industries.

Another assumption is to strengthen the smart specialisation of regions, which even if they currently show the largest potential growth, then in the future there is no certainty whether this trend will continue.

In Polish cluster policy, the creation of clusters by the top-down method has disappeared, which in many cases led to the creation of artificial clusters, which in the long-term did not have a chance for development. This method in many cases underlies the creation of so-called "wishful thinking clusters", in which the national or local government is convinced of the possibility of creating a cluster in a given region, which does not evaluate into actual cluster ties. It is necessary to agree with the view presented by Lindqvist, Ketels and Sölvell, who stated ,that cluster policy is significantly more likely to be beneficial if it is focused on leveraging rather than creating clusters. In essence, governments lack the knowledge to evaluate where new clusters could emerge in welfare-enhancing ways given the appropriate policy intervention "[10].

When assessing the Polish cluster policy, it should be stated that by conducting recruitment to the key clusters program, it fulfils the recommendations presented in the European Union documents, especially in the Smart Guide to Cluster Policy document from 2016. First of all, it does not only support individual specialised firms, focusing mainly on merging entities or clusters. No new clusters are created, but it supports the strong sides of already existing clusters, offering them a diversified set of support. The policy promotes strategic clusters with development potential, basing their choice on regional competences and smart specialisation. This policy, which should be particularly emphasised, is implemented in conjunction with other policies pursued in the country, such as industrial or innovative policy, mutually complementing.

\section{Conclusions}

Cluster policy is a set of tools used by the state to support clusters in individual national economies. Two basic assumptions can be made regarding the identification and selection of clusters to support. First of all, cluster policy can support new cluster initiatives that are just being created, and cluster companies do not have a common history of operations. On the one hand, this is an effective measure, as the policy supports new clusters created using the top-down method. On the other hand, it leads to the process of excessive creation of clusters, which are often set up only to obtain financial support from the state. Secondly, cluster policy can support already existing clusters where whose common activity can be documented and which have been successful in joint projects. These clusters were selected to receive much support from the government and can further develop the cluster. In both cases, those clusters that include small and medium enterprises are in the focus of attention [7].

Polish cluster policy is relatively recently introduced, and it rather fulfils the assumptions of European cluster policy, without proposing own innovative tools or solutions. The concept of selecting clusters - leaders in the form of key national clusters, 
is to bring about the effect of the better use of funds and building national champions. However, the cluster policy should be looked a bit wider. It should not create a group of entities with privileged access to selected forms of public support, including huge financial, training, marketing and consulting resources. This can lead to huge disproportions between clusters and regions. Already there are regions in Poland where there are three such clusters and regions in which none exist. As a consequence, there will be a deepened specialisation of some regions compared to others, which will be influenced by the policy and not the market. Cluster policy based on key clusters is currently observed a trend in the cluster policy of various countries, but it is not free from defects, and its effects will be difficult to measure.

\section{References}

1. Borrás, S., Tsagdis, D.: Cluster policies in Europe, Edward Elgar Publishing, Cheltenham (2008).

2. Dzierżanowski, M. (ed.): Directions and assumptions of Polish cluster policy until 2020 Recommendations of the Working Group for Cluster Policy, Warsaw (2012).

3. Europe 2020: A European strategy for smart, sustainable and inclusive growth, Brussels, 3.3.2010 COM (2010) 2020 .

4. Hołub-Iwan, J., Wielec, Ł.: Opracowanie systemu wyboru Krajowych Klastrów Kluczowych, Część I: Charakterystyka Krajowego Klastra Kluczowego w oparciu o analizę źródeł wtórnych, Polska Agencja Rozwoju Przedsiębiorczości, Warszawa (2014).

5. Hołub-Iwan, J., Wielec Ł.: Opracowanie systemu wyboru Krajowych Klastrów Kluczowych, Część II: Opis systemu wyboru Krajowych Klastrów Kluczowych w Polsce, Polska Agencja Rozwoju Przedsiębiorczości, Warszawa (2014).

6. Jankowiak, A.H.: Cluster Policy Models in the VISEGRAD Group Countries - A Comparative Study, w: Transformations in Business \& Economics, vol. 17, nr 2A, (2018).

7. Jankowiak, A.H.: Industrial clusters as an important factor for development of micro, small and medium-sized enterprises (MSMEs), International Days of Statistics and Economics, Conference Proceedings, T. Löster, T. Pavelka (eds.) Libuše Macáková, Melandrium, (2018).

8. Konstantynova, A., Wilson, J.: Comparing Cluster Policies: An Analytical Framework, Okestra - Working Paper Series- R01:1-33, Basque Institute of Competitiveness (2014). [5]

9. Lehmann, E.E., Menter, M.: Public cluster policy and performance, Technol Transf (2018) 43: 558. DOI:10.1007/s10961-017-9626-4.

10. Lindqvist, G., Ketels, Ch., Sölvell, Ö.: The Cluster Initiative Greenbook 2.0., Ivory Tower Publishers, Stockholm (2013).

11. Nishimura, J., Okamuro, H.: Subsidy and networking: The effects of direct and indirect support programs of the cluster policy, Research Policy Volume 40, Issue 5, June 2011, Pages 714-727, DOI: 10.1016/j.respol.2011.01.011.

12. Njøs, R., Jakobsen, S.-E., Wiig Aslesen, H., Fløysand, A.: Encounters between cluster theory, policy and practice in Norway: Hubbing, blending and conceptual stretching, European Urban and Regional Studies, vol. 24, 3: 274-289 (2017), DOI 10.1177/0969776416655860.

13. Park, S.C.: The Fourth Industrial Revolution and implications for innovative cluster policies, AI \& Soc (2018) 33: 433. DOI:10.1007/s00146-017-0777-5. 
14. Polozhentseva, Y., Klevtsova, M.: Instruments of Development of Cluster Policy: Stages, Models, International Practice, Procedia Economics and Finance Volume 27, 2015, Pages 529-537, DOI: 10.1016/S2212-5671(15)01029-1.

15. Smart Guide to Cluster Policy, European Union, 2016, Ref. Ares (2016)2507138 $31 / 05 / 2016$.

16. Strategia Rozwoju Kraju do 2020, Warszawa (2012), http://ww.mrr.gov.pl, last access 2018/09/25 